\title{
Lowering of triglycerides by gemfibrozil affects neither the glucoregulatory nor antilipolytic effect of insulin in Type 2 (non-insulin-dependent) diabetic patients
}

\author{
H. Vuorinen-Markkola ${ }^{1}$, H. Yki-Järvinen ${ }^{1}$ and M-R. Taskinen ${ }^{2}$ \\ ${ }^{1}$ Second and ${ }^{2}$ Third Departments of Medicine, University of Helsinki, Helsinki, Finland
}

\begin{abstract}
Summary. Hypertriglyceridaemia and insulin resistance are closely associated but it is unknown whether hypertriglyceridaemia per se contributes to insulin resistance. In the present study we examined whether gemfibrozil, by lowering triglyceride levels, improves the glucoregulatory and antilipolytic action of insulin in Type 2 (non-insulin-dependent) diabetes mellitus. Twenty patients were randomly allocated to receive either placebo or gemfibrozil $1200 \mathrm{mg}$ daily for 12 weeks in a double-blind study. Very low density lipoprotein triglyceride levels decreased in the gemfibrozil group by $42 \pm 12 \%$ $(p<0.01)$. Gemfibrozil had no effect on the diurnal concentration of non-esterified fatty acids (NEFA). At the randomization $\mathrm{HbA}_{1 \mathrm{c}}$ levels were comparable (7.6 \pm 0.3 vs $7.8 \pm 0.2 \%$, NS) and increased slightly both in the gemfibrozil (8.2 \pm $0.4 \%, p<0.05)$ and placebo groups $(8.0 \pm 0.3 \%, \mathrm{NS})$. Preand post-treatment diurnal glucose and insulin concentrations remained unchanged. Basal pre- and post-treatment hepatic glucose production rates were comparable in both groups and similarly suppressed by insulin. Rate of whole
\end{abstract}

body glucose disposal during a low-dose insulin infusion (serum insulin $\sim 90 \mathrm{pmol} / \mathrm{l}$ ) (pre- vs post-gemfibrozil $11.9 \pm$ 1.1 vs $11.1 \pm 0.7$, pre- vs post-placebo $9.9 \pm 1.1$ vs $10.8 \pm$ $0.8 \mu \mathrm{mol} \cdot \mathrm{kg}^{-1} \cdot \mathrm{min}^{-1}$, NS for both) and a high-dose insulin infusion (serum insulin $\sim 500 \mathrm{pmol} / 1)(16.2 \pm 1.7$ vs $17.7 \pm 2.7$, $17.1 \pm 4.2$ vs $17.4 \pm 2.9 \mu \mathrm{mol} \cdot \mathrm{kg}^{-1} \cdot \mathrm{min}^{-1}$, respectively, NS for both) remained unchanged. Basal pre- and post-treatment NEFA turnover rates were comparable in both groups and similarly suppressed by insulin. Also rates of total lipid oxidation, plasma NEFA oxidation and non-oxidative NEFA metabolism remained unchanged in both groups. We conclude that gemfibrozil effectively lowers serum triglycerides but has no effect on insulin sensitivity of glucose and NEFA metabolism. The data suggest that hypertriglyceridaemia is a consequence rather than a cause of insulin resistance in Type 2 diabetic patients.

Key words: Triglycerides, gemfibrozil, insulin resistance, Type 2 (non-insulin-dependent) diabetes mellitus.
Hypertriglyceridaemia, a decreased high density lipoprotein (HDL) cholesterol concentration, hyperinsulinaemia and insulin resistance are metabolic abnormalities which co-exist in Type 2 (non-insulin-dependent) diabetic patients. The concentration of serum triglycerides is correlated with insulin resistance in normolipidaemic subjects with normal glucose tolerance, in subjects with impaired glucose tolerance and in Type 2 diabetic patients [1-3]. Subjects with endogenous hypertriglyceridaemia and normal glucose tolerance also exhibit resistance to both the antilipolytic and glucoregulatory actions of insulin [2-5]. It is, however, unclear whether hypertriglyceridaemia is a consequence of insulin resistance or whether it has a direct deleterious action on glucose metabolism.

It is well-established that insulin has multiple sites of action on very low density lipoprotein (VLDL) production in the liver [6]. Thus, insulin resistance could lead to increased VLDL production and elevation of serum tri- glycerides $[7,8]$. Indeed, recent epidemiological data disclosed that insulin resistance precedes the development of hypertriglyceridaemia [9]. Since suppression of non-esterified fatty acids (NEFA) by insulin is impaire not only in Type 2 diabetic patients [10] but also in hypertriglyceridaemic subjects [2] an increased availability of circulating NEFA could impair insulin action on glucose metabolism in both disorders. Notably, elevation of triglyceride and NEFA concentrations by Intralipid inhibits insulinstimulated glucose uptake during hyperinsulinaemia but it is unclear whether NEFA or triglycerides mediate this effect $[11,12]$.

Gemfibrozil exerts multiple actions on VLDL metabolism. The major action of gemfibrozil is to enhance the hydrolysis of triglyceride rich particles by increasing lipoprotein lipase activity [13]. Kinetic data suggest that the drug also inhibits VLDL triglyceride production [14]. However, the mechanisms by which fibric acid derivates de- 
Table 1. Clinical characteristics of the Type 2 diabetic patients at randomization

\begin{tabular}{lcc}
\hline & $\begin{array}{l}\text { Gemfibrozil } \\
\text { group }\end{array}$ & Placebo group \\
\hline Sex (male/female) & $8 / 2$ & $10 / 0$ \\
Age (years) & $60 \pm 2$ & $52 \pm 3$ \\
Duration of diabetes (years) & $10 \pm 2^{\mathrm{a}}$ & $5 \pm 1$ \\
Body mass index (kg/m $\left.{ }^{2}\right)$ & $27.1 \pm 0.7$ & $27.4 \pm 0.7$ \\
Waist to hip ratio & $0.97 \pm 0.02$ & $1.03 \pm 0.01$ \\
Systolic blood pressure (mm Hg) & $150 \pm 5$ & $148 \pm 5$ \\
Diastolic blood pressure $(\mathrm{mm} \mathrm{Hg})$ & $91 \pm 3$ & $91 \pm 4$ \\
HbA 1 (\%) & $7.6 \pm 0.3$ & $7.8 \pm 0.2$ \\
C-peptide (nmol/l) & $0.86 \pm 0.07$ & $0.98 \pm 0.11$ \\
Fasting glucose (mmol/l) & $9.3 \pm 0.5$ & $9.0 \pm 0.6$ \\
\hline
\end{tabular}

${ }^{a} p<0.05$ vs placebo group

crease VLDL synthesis have not been clearly defined. Kissebah et al. [15] suggested that both the turnover rate and the mass of plasma NEFA decrease during gemfibrozil therapy indicating that gemfibrozil might be antilipolytic. Studies with isolated adipocytes have also indicated that gemfibrozil is antilipolytic [16, 17]. If gemfibrozil has indeed antilipolytic action this could explain its inhibitory effect on VLDL triglyceride synthesis.

The major aim of the present study was to test whether lowering of serum triglycerides by gemfibrozil affects the glucoregulatory effect of insulin in Type 2 diabetic patients with moderate hypertriglyceridaemia. In addition we studied whether gemfibrozil modulates NEFA metabolism or the antilipolytic action of insulin. If this were the case, it might be possible to treat both hypertriglyceridaemia and hyperglycaemia in these patients with a single drug.

\section{Patients and methods}

Patients. Twenty Type 2 diabetic patients participated in the study. Their clinical characteristics are shown in Table 1 . Patients with serum triglycerides between 1.50 to $4.50 \mathrm{mmol} / \mathrm{l}$ were considered acceptable for the study. This range of triglycerides was selected based on our previous data which demonstrated an inverse relationship between serum triglycerides lower than $4.5 \mathrm{mmol} / \mathrm{l}$ and glucose disposal at physiological insulin concentrations $[1,2]$. The mean serum triglyceride concentration of the patients at the 6-week pre-treatment visit was $2.85 \pm 0.30 \mathrm{mmol} / \mathrm{l}$. Endocrine and other disorders that could influence glycaemic control or lipoprotein metabolism were excluded by history and physical examination, and by liver, kidney, and thyroid function tests. All patients were treated with oral hypoglycaemic agents (gemfibrozil group: sulphonylurea $n=4$, sulphonylurea and biguanide $n=5$, sulphonylurea, biguanide and guarem $n=1$, placebo group: sulphonylurea $n=5$, sulphonylurea and biguanide $n=2$, sulphonylurea and guarem $n=2$, sulphonylurea, biguanide and guarem $n=1$ ). The oral antidiabetic agents were continued unchanged throughout the study. The patients had no signs of clinically significant micro- or macrovascular diabetic complications. The nature and potential risks of the study were explained in detail to each patient before they gave their informed consent to participate. The study protocol was approved by the Ethical Committee of the Helsinki University Central Hospital.

Study design. During the 6-week pre-treatment period, all subjects received two tablets of placebo twice daily (single blind). Glycaemic control and serum lipid concentrations were measured at 3 and 6 weeks during the pre-treatment period. At these visits the patients were seen by a nurse trained in diabetes care and they were given dietary instruction. The target diet for the patients included $30 \%$ of the energy as fat, $55 \%$ as carbohydrate and $15 \%$ as protein. Serum triglyceride and cholesterol concentrations did not change during the pre-treatment period (data not shown). Thereafter the patients were admitted to the metabolic ward (week 0 ) for the metabolic tests, where they continued on the weight-maintaining diet. The patients were then randomly allocated (double blind) to receive either placebo (two tablets twice daily) or gemfibrozil (two $300 \mathrm{mg}$ tablets twice daily) for 12 weeks, and discharged from the hospital. The patients visited the out-patient clinic at 4 and 8 weeks and they were readmitted to the metabolic ward at 12 weeks for final metabolic tests. The weight and blood pressure of the patients were unchanged during the pre-treatment period (data not shown).

Laboratory tests during the 6-week pre-treatment and 12-week treatment period. At each visit blood was withdrawn for determination of the fasting blood glucose, $\mathrm{HbA}_{1 c}$, serum triglyceride and total cholesterol concentrations. At 0 and 12 weeks the concentrations of serum VLDL triglycerides, low density lipoprotein (LDL) cholesterol and HDL cholesterol were also measured.

Metabolic tests at 0 and 12 weeks. On day 1 after admission, blood glucose, serum insulin, triglyceride and plasma NEFA concentrations were determined in blood samples taken at 07.30, 11.30, 12.00, $16.00,20.00,24.00,04.00$, and 08.00 hours. Blood pressure was measured after 5 to $10 \mathrm{~min}$ rest in the sitting position with a random zero sphygmomanometer (Random Zero Sphygmomanometer; Hawksley \& Sons, Lancing, UK).

On day 2, after an overnight fast, glucose and NEFA kinetics and oxidation rates were measured between 08.00 and 13.00 hours as depicted in Figure 1. Each study consisted of a basal period (0-60 min) and two hyperinsulinaemic periods (60-180 min, low-dose insulin infusion; 180-300 min, high-dose insulin infusion). Rates of glucose appearance $\left(R_{a}\right)$ and disappearance $\left(R_{d}\right)$ were determined using an infusion of $\left[3-{ }^{3} \mathrm{H}\right]$ glucose, and plasma NEFA kinetics using [1$\left.{ }^{14} \mathrm{C}\right]$ palmitate-labelled albumin. During hyperinsulinaemia, plasma glucose was maintained constant using the insulin clamp technique as previously described $[18,19]$. These measurements were combined with indirect calorimetry to determine substrate oxidation rates as well as with collection of expired $\mathrm{CO}_{2}$ for calculation of plasma NEFA oxidation as described below.

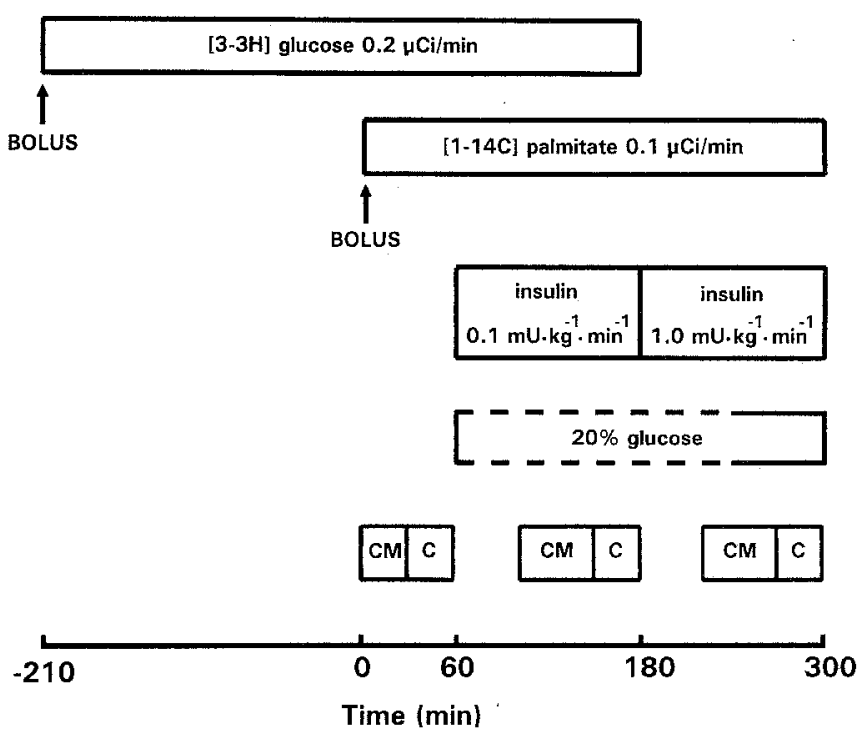

Fig.1. Design of the determination of glucose and non-esterified fatty acid (NEFA) kinetics and oxidation rates. CM indicates the time of indirect calorimetry measurements and $\mathrm{C}$ respective measurements of plasma NEFA oxidation 
Table 2. Concentrations ( $\mathrm{mmol} / \mathrm{l})$ of serum lipids and lipoproteins

\begin{tabular}{|c|c|c|c|c|}
\hline & \multicolumn{2}{|c|}{ Gemfibrozil group } & \multicolumn{2}{|c|}{ Placebo group } \\
\hline & week 0 & week 12 & week 0 & week 12 \\
\hline Total triglycerides & $2.99 \pm 0.37$ & $1.80 \pm 0.17^{\mathrm{a}}$ & $3.14 \pm 0.40$ & $4.20 \pm 1.13$ \\
\hline Total cholesterol & $5.73 \pm 0.36$ & $5.88 \pm 0.30$ & $5.42 \pm 0.30$ & $5.25 \pm 0.31$ \\
\hline LDL cholesterol & $3.30 \pm 0.26$ & $3.84 \pm 0.27$ & $3.01 \pm 0.30$ & $2.44 \pm 0.28^{\mathrm{a}}$ \\
\hline HDL cholesterol & $1.15 \pm 0.06$ & $1.24 \pm 0.06^{\mathrm{a}}$ & $1.05 \pm 0.07$ & $1.04 \pm 0.10$ \\
\hline IDL chol/HDL chol & $2.88 \pm 0.17$ & $3.13 \pm 0.16$ & $2.91 \pm 0.25$ & $2.41 \pm 0.26$ \\
\hline
\end{tabular}

${ }^{\mathrm{a}} p<0.05,{ }^{\mathrm{b}} p<0.01$ vs week 0

\section{Methods}

Whole body glucose disposal. For measurement of glucose $\mathrm{R}_{\mathrm{a}}$ and $\mathrm{R}_{\mathrm{d}}$ in the basal state, and during the low-dose insulin infusion, a primed continuous $(0.2 \mu \mathrm{Ci} / \mathrm{min})$ infusion of $\left[3-{ }^{3} \mathrm{H}\right]$ glucose (Amersham International, Amersham, Bucks, UK) was started at 04.30 and continued until 11.00 hours (from -210 to $180 \mathrm{~min}$ ). We chose not to measure hepatic glucose production (HGP) during high-dose insulin infusion since our previous studies [20] as well as those of the others had shown that reliable measurements cannot be obtained if glucose specific activity changes rapidly. When measured in normal subjects under conditions where glucose specific activity is held constant, HGP is entirely suppressed in the presence of hyperinsulinaemia comparable to that in the present study [21] but this does not necessarily imply normal suppression in patients with Type 2 diabetes. Thus, the rate of glucose infused during the high-dose insulin infusion reflects overall insulin resistance rather than merely peripheral insulin resistance. The priming dose, which was given as a bolus during $10 \mathrm{~min}$, was adjusted according to the fasting blood glucose concentration on day 1 to achieve constant glucose specific activity [22]. Glucose specific activity $[23,24]$ was measured at $0,30,60,150$ and $180 \mathrm{~min}$.

At $60 \mathrm{~min}$, a primed continuous infusion of insulin $(0.1 \mathrm{mU}$. $\mathrm{kg}^{-1} \cdot \mathrm{min}^{-1}$, Actrapid HM, Novo, Copenhagen, Denmark) was started to increase and maintain serum insulin at $\sim 90 \mathrm{pmol} / 1$ [18]. Plasma glucose was measured every 5 to $10 \mathrm{~min}$ in blood samples taken from arterialized venous blood, and $20 \%$ glucose was infused to maintain blood glucose at its fasting level. At $180 \mathrm{~min}$, the serum insulin concentration was increased and maintained at $-500 \mathrm{pmol} / 1$ (insulin infusion rate of $1.0 \mathrm{mU} \cdot \mathrm{kg}^{1} \cdot \mathrm{min}^{-1}$ ). Plasma glucose concentration was allowed to reach normoglycaemia and it was kept constant thereafter. Serum free insulin concentrations were measured at $0,60,90,150,180,210,270$ and $300 \mathrm{~min}$.

Glucose $R_{a}$ and $R_{d}$ were calculated according the non-steadystate equation of Steele [23], assuming a glucose distribution volume of $200 \mathrm{~m} 1 / \mathrm{kg}$ and a pool fraction of 0.65 . Use of this model leads, under some conditions, to underestimation of glucose $R_{a}$ and $R_{d}[20]$. To avoid these errors the basal period lasted $270 \mathrm{~min}$ instead of the usual 120-180 $\mathrm{min}$.

Respiratory exchange measurements. Indirect calorimetry measurements were performed with a computerized flow-through canopy gas analyser system (Deltatrac Metabolic Monitor; Datex Helsinki, Finland) as depicted in Figure 1 and as previously described in detail $[12,24,25]$. The protein oxidation rate was estimated from urinary urea nitrogen excretion. Non-oxidative glucose $R_{d}$ was defined as the difference between total $R_{d}$ and oxidative $R_{d}$.

Plasma NEFA turnover and oxidation measurements. $\left[1-{ }^{14} \mathrm{C}\right]$ palmitate (New England Nuclear, Boston, Mass, USA) complexed to albumin (SPR, Helsinki, Finland) was used for measurement of plasma NEFA turnover, as previously described [26]. A priming dose of $6 \mu \mathrm{Ci}\left[1-{ }^{14} \mathrm{C}\right]$ palmitate-albumin was given at $0 \mathrm{~min}$, and $0.1 \mu \mathrm{Ci} / \mathrm{min}$ of $\left[1-{ }^{14} \mathrm{C}\right]$ palmitate-albumin solution was infused between 0-300 min. Use of these isotope doses results in constant plasma NEFA specific activity within $30 \mathrm{~min}$ [26]. Serum triglycerides, plasma glycerol [27] and NEFA concentrations [28] and NEFA specific activity [26] were measured in blood samples taken at $0,30,60$, $150,180,270$ and $300 \mathrm{~min}$.

To determine the rate of plasma NEFA oxidation during the [1${ }^{14} \mathrm{C}$ ]palmitate infusion, the specific activity of expired air $\mathrm{CO}_{2}$ was measured as depicted in Figure 1 and as previously described [24, 29, 30]. The bicarbonate pool was primed with $5 \mu \mathrm{Ci}$ of $\mathrm{NaH}^{14} \mathrm{CO}_{3}(\mathrm{New}$ England Nuclear) given as a bolus at $0 \mathrm{~min}$ [29]. Plasma NEFA oxidation could be reliably determined in 12 of 20 patients in whom constant $\mathrm{CO}_{2}$ specific activity was achieved.

The rate of plasma NEFA oxidation was calculated as follows: plasma NEFA oxidation rate $\left(\mu \mathrm{mol} \cdot \mathrm{kg}^{-1} \cdot \mathrm{min}^{-1}\right)=\mathrm{SA}$ ${ }^{14} \mathrm{CO}_{2} \cdot \mathrm{VCO}_{2} /\left(\mathrm{C} \times \mathrm{SA}\left[{ }^{14} \mathrm{C}\right] \mathrm{NEFA}\right)$ where $\mathrm{SA}^{14} \mathrm{CO}_{2}$ is the specific activity of $\mathrm{CO}_{2}$ in expired air $(\mathrm{dpm} / \mu \mathrm{mol}), \mathrm{VcO}_{2}$ is the total $\mathrm{CO}_{2}$ production rate $\left(\mu \mathrm{mol} \cdot \mathrm{kg}^{-1} \cdot \mathrm{min}^{-1}\right)$, SA $\left[{ }^{14} \mathrm{C}\right] \mathrm{NEFA}$ is the specific activity of $\left[{ }^{14} \mathrm{C}\right] \mathrm{NEFA}$ in plasma (dpm/ $/ \mathrm{mol}$ ), and $\mathrm{C}=0.81$, the retention factor to correct for labelled $\mathrm{CO}_{2}$ retained in the bicarbonate pool [29]. Use of this technique to determine plasma NEFA oxidation has recently been revalidated [30]. Non-plasma NEFA oxidation $[10,24,30]$ which is the difference between total lipid oxidation and plasma NEFA oxidation expressed as palmitate oxidation, and NEFA turnover $[24,31-33]$ were calculated as previously described in detail.

\section{Analytical procedures}

Blood glucose concentrations were measured by the glucose dehydrogenase method (Gluc-DH; Merck Oy, Darmstadt, FRG). During the metabolic test on day 2 glucose was determined in plasma by the glucose oxidase method [34], using the Beckman Glucose Analyzer II (Beckman Instruments, Fullerton, Calif., USA). Serum insulin concentrations were determined by RIA [35] using the Phadeseph insulin RIA kit (Pharmacia, Uppsala, Sweden). Serum free insulin concentrations were determined by RIA [35] after precipitation with polyethylene glycol. Serum C-peptide was determined by RIA using the RIA-mat C-Peptid II kit (BYK-Sangtec Diagnostica $\mathrm{GmbH}$, Frankfurt, FRG; [36]). $\mathrm{HbA}_{\mathrm{lc}}$ (reference range $4.0-6.0 \%$ ) was measured with ion exchange high performance liquid chromatography using the fully automated Glycosylated Hemoglobin Analyzer System (Bio-Rad, Richmond, Calif., USA; [37]). Serum and lipoprotein cholesterol and triglyceride concentrations were determined enzymatically (kit nos. 0722138 and 0715166; Hoffmann-La Roche, Basel, Switzerland) with an automated Cobas Mira analyser (Hoffmann-La Roche). VLDL, LDL and HDL were spearated by ultracentrifugation at $100,000 \mathrm{~g}$ in a Beckman L7-70 ultracentrifuge as previously described in detail [38].

\section{Statistical analysis}

Comparisons between 0 and 12 week study occasions, and between study groups were performed using BMDP program $4 \mathrm{~V}$ for analysis of variance and covariance with repeated measures, followed by 

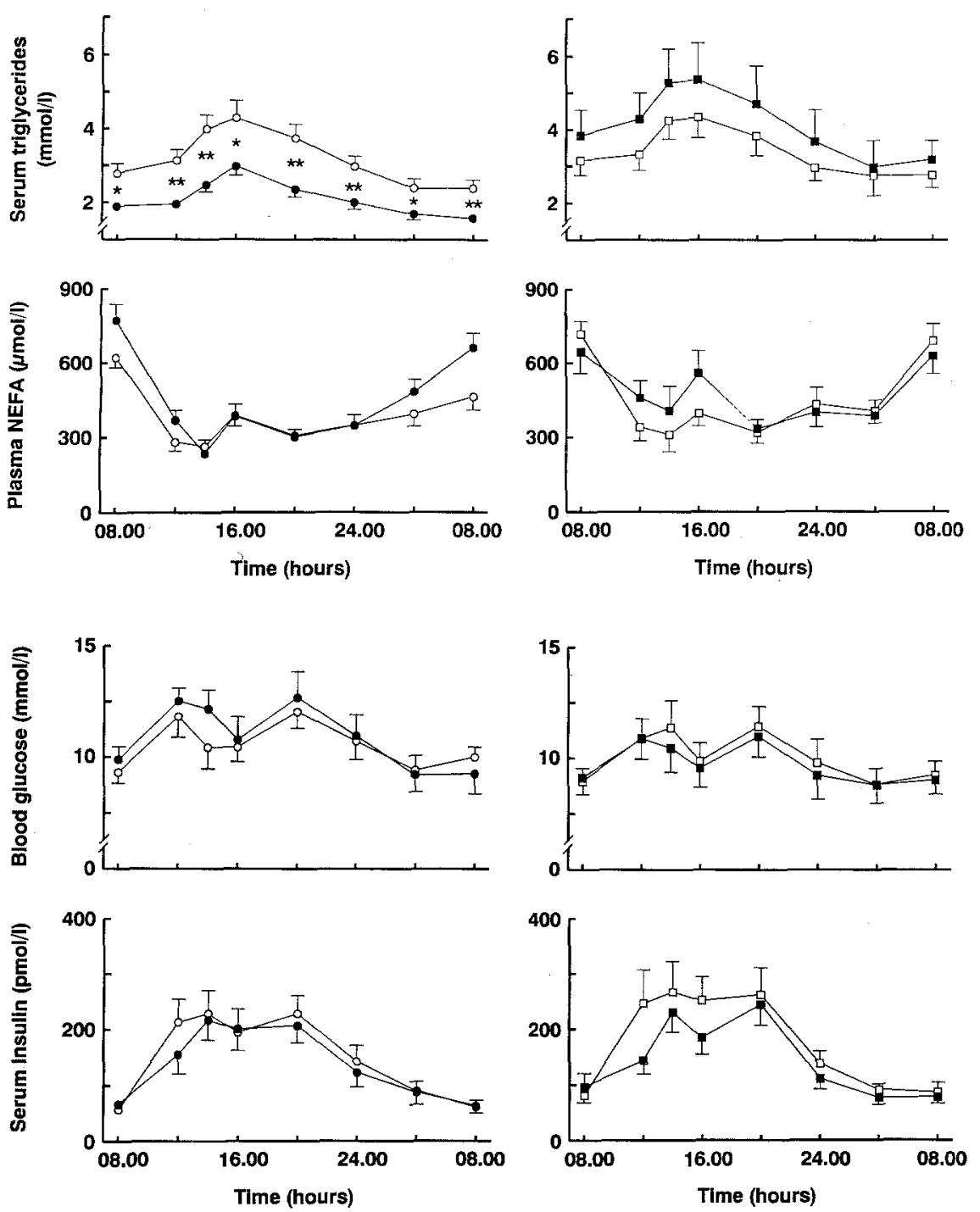

Fig. 2. Serum triglyceride and plasma non-esterified fatty acid concentrations (24-h profiles) in the gemfibrozil $(0,0)$ and placebo group $(\square, \mathbf{a})$. Open symbols represent pre-treatment values and solid symbols posttreatment values, respectively. Analysis of variance and covariance with repeated measures followed by paired $t$-test was used for statistical analyses. ${ }^{*} p<0.05,{ }^{* *} p<0.01$ pre- vs post-treatment
Fig. 3. Plasma glucose and serum insulin concentrations ( $24-\mathrm{h}$ profiles) in the gemfibrozil $(O, \bullet)$ and placebo group $(\square, \boldsymbol{\square})$. Open symbols represent pre-treatment values and solid symbols post-treatment values, respectively paired and unpaired $t$-test analyses. Correlation analyses were performed with simple regression analyses. In the case of non-normal distribution, log-transformation of the data was performed. All data are shown as mean \pm SEM.

\section{Results}

Serum lipids. At randomization, serum triglyceride, total HDL and LDL cholesterol concentrations were comparable in the gemfibrozil and placebo groups. Fasting VLDL triglycerides fell in the gemfibrozil group by $42 \pm 12 \% \quad(p<0.01)$, but remained unchanged in the placebo group (Table 2). Serum HDL cholesterol also rose slightly in the gemfibrozil group $(p<0.05)$ but not in the placebo group (Table 2). The serum LDL cholesterol concentration rose slightly but not significantly in the gemfibrozil group whereas there was a modest decrease in the placebo group. The LDL/HDL cholesterol and total/HDL cholesterol ratios remained unchanged in both groups (Table 2).

Figure 2 shows $24-\mathrm{h}$ profiles of triglyceride and plasma NEFA concentrations. The mean 24 -h pre-treatment tri- glyceride concentration was $3.24 \pm 0.29 \mathrm{mmol} / 1$ in the gemfibrozil group and $3.42 \pm 0.43 \mathrm{mmol} / \mathrm{l}$ (NS) in the placebo group. During gemfibrozil treatment the mean 24-h serum triglyceride concentration fell by $29 \pm 9 \%$ $(p<0.01)$. In the placebo group there was a trend towards an increase in serum triglycerides. There were no differences in the pre- vs post-treatment mean concentrations of 24-h NEFA in the gemfibrozil group (384 \pm 23 vs $441 \pm 26 \mu \mathrm{mol} / \mathrm{l}, \mathrm{NS}$ ) or in the placebo group ( $450 \pm 45 \mathrm{vs}$ $534 \pm 81 \mu \mathrm{mol} / 1, \mathrm{NS}$, respectively).

Glycaemic control and serum insulin concentrations. At randomization the $\mathrm{HbA}_{1 \mathrm{c}}$ levels were comparable in both groups (Table 1). During the treatment period $\mathrm{HbA}_{1 \mathrm{c}}$ increased slightly both in the gemfibrozil $(8.2 \pm 0.4 \%$, $p<0.05)$ and placebo group $(8.0 \pm 0.3 \%$, NS $)$. There were no differences in pre- vs post-treatment mean 24 -h blood glucose concentrations either in the gemfibrozil (10.4 \pm 0.6 vs $11.0 \pm 0.7 \mathrm{mmol} / \mathrm{l})$ or placebo group $(10.0 \pm 0.8 \mathrm{vs}$ $9.8 \pm 0.7 \mathrm{mmol} / \mathrm{l}$, respectively, Fig. 3 ). The mean 24 - $\mathrm{h}$ serum insulin concentration during the pre-treatment period was $153 \pm 24 \mathrm{pmol} / \mathrm{l}$ in the gemfibrozil and $180 \pm$ $27 \mathrm{pmol} / 1$ in the placebo group (NS), and no changes oc- 


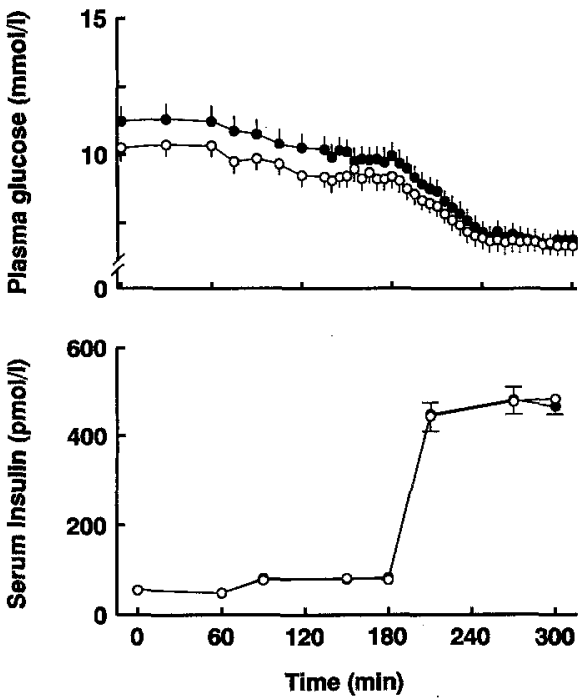

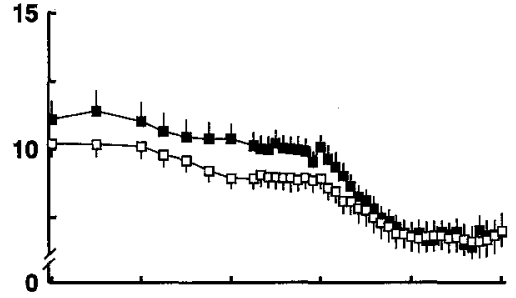

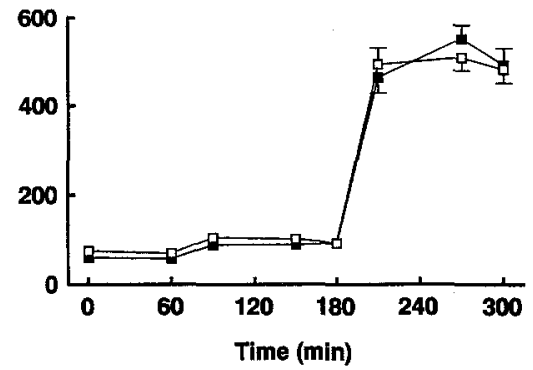

Fig.4. Plasma glucose and serum insulin concentrations during the 6 -h periods of the metabolic tests in the gemfibrozil $(0,0)$ and placebo group $(\square, \boldsymbol{\square})$. Open symbols represent pre-treatment values and solid symbols post-treatment values, respectively curred during treatment periods $(138 \pm 23$ and $147 \pm$ $18 \mathrm{pmol} / 1$, respectively, Fig. 3 ).

Plasma glucose and serum free insulin concentrations during the metabolic tests. Plasma glucose and serum free insulin concentrations during the 6-h periods of metabolic testing are presented in Figure 4. The pre- vs post-treatment fasting glucose concentrations were comparable in the gemfibrozil and placebo groups $(10.4 \pm 0.1$ vs $11.3 \pm$ $0.6 \mathrm{mmol} / 1$, and $10.2 \pm 0.4 \mathrm{vs} 11.1 \pm 0.7 \mathrm{mmol} / \mathrm{l}$, respectively). During the low-dose insulin infusion, the post-treatment plasma glucose concentration was slightly higher both in the gemfibrozil $(9.9 \pm 0.4 \mathrm{mmol} / 1, p<0.05)$ and placebo group $(10.0 \pm 0.4 \mathrm{mmol} / \mathrm{l}, \mathrm{NS})$ than in the pretreatment studies $(9.2 \pm 0.4$ and $8.9 \pm 0.4 \mathrm{mmol} / 1$, respectively). During the high-dose insulin infusion pre- vs posttreatment plasma glucose concentrations were similar in both groups $(6.8 \pm 0.4$ vs $6.8 \pm 0.4$, and $6.7 \pm 0.6$ vs $6.9 \pm$ $0.5 \mathrm{mmol} / 1$, respectively) (Fig. 4). Serum free insulin concentrations were similar between the two groups during the insulin infusions (Fig. 4).

Glucose metabolism. Pre-treatment rates of hepatic glucose production (glucose $R_{a}$ ) in the basal state were similar in the gemfibrozil and placebo groups $(12.3 \pm 5.0$ and $12.1 \pm 1.1 \mu \mathrm{mol} \cdot \mathrm{kg}^{-1} \cdot \mathrm{min}^{-1}$, NS) and did not change during treatment $\left(12.7 \pm 0.7\right.$ and $11.1 \pm 1.0 \mu \mathrm{mol} \cdot \mathrm{kg}^{-1} \cdot \mathrm{min}^{-1}$, NS, respectively, Table 4). Also, the low-dose insulin infusion suppressed hepatic glucose production similarly in both groups (pre- vs post-gemfibrozil $9.0 \pm 1.0$ vs $8.5 \pm 1.0$, pre- vs post-placebo $7.1 \pm 1.2$ vs $7.4 \pm 1.0 \mu \mathrm{mol}$. $\mathrm{kg}^{-1} \cdot \min ^{-1}$, NS for both, Table 4).

The pre- and post-treatment rates of total glucose disposal (glucose $R_{d}$ ) in the basal state, and during the lowand high-dose insulin infusions were similar in both groups (Table 4). Since the glucose level was slightly different in the pre- and post-treatment studies during the low-dose insulin infusion, the glucose clearance rates (glucose $R_{d}$ divided by the ambient glucose concentration) were calculated. The glucose clearance rates also remained unchanged (data not shown). In both groups the basal rates of glucose oxidation and non-oxidative glucose disposal (glucose $\mathrm{R}_{\mathrm{d}}$ - oxidation) did not change during the treatment period. Also during the low- and high-dose insulin infusion, the pre- and post-treatment rates of glucose oxidation and non-oxidative glucose disposal were similar (Table 4).

NEFA metabolism. The plasma NEFA turnover rates were equal in both groups (Table 3 ). Insulin suppressed plasma NEFA turnover rates in an identical fashion in both groups. Overall the plasma NEFA concentrations paralleled the changes in plasma NEFA turnover rates (Table 3).

Pre- and post-treatment rates of total lipid oxidation, plasma and non-plasma NEFA oxidation, and non-oxidative NEFA metabolism were similar in the gemfibrozil group in the basal state as well as during the low- and highdose insulin infusions. In the placebo group, the pre- and post-treatment basal lipid metabolism were similar. During the low-dose insulin infusion total lipid oxidation tended to increase (NS) and a slight increase was seen in non-plasma NEFA oxidation while plasma NEFA oxidation did not change after treatment period. During the high-dose insulin infusion the pre- and post-treatment rates of lipid metabolism were similar in the placebo group (Table 3).

Serum triglyceride and plasma glycerol concentrations during the metabolic tests. Serum triglycerides (data not shown) and plasma glycerol concentrations were suppressed similarly by insulin in both groups and in both studies. In the gemfibrozil group pre- vs post-treatment plasma glycerol concentrations in the basal state were $90 \pm 7$ vs $81 \pm 7 \mu \mathrm{mol} / 1$ (NS) and were decreased by the low-dose insulin infusion to $63 \pm 5$ vs $55 \pm 5 \mu \mathrm{mol} / \mathrm{l}$ (NS), and by the high-dose insulin infusion to $44 \pm 4$ vs $37 \pm 4 \mu \mathrm{mol} / 1$ (NS), respectively. The corresponding pre- vs post-treatment concentrations in the placebo group were $75 \pm 5$ vs $85 \pm 8 \mu \mathrm{mol} / 1$ (NS), $63 \pm 7$ vs $64 \pm 6 \mu \mathrm{mol} / \mathrm{l}(\mathrm{NS})$ and $39 \pm 4 \mathrm{vs} 47 \pm 7 \mu \mathrm{mol} / \mathrm{l}$ (NS), respectively. 
Table 3. Plasma NEFA metabolism during the basal state and low-dose and high-dose insulin infusion

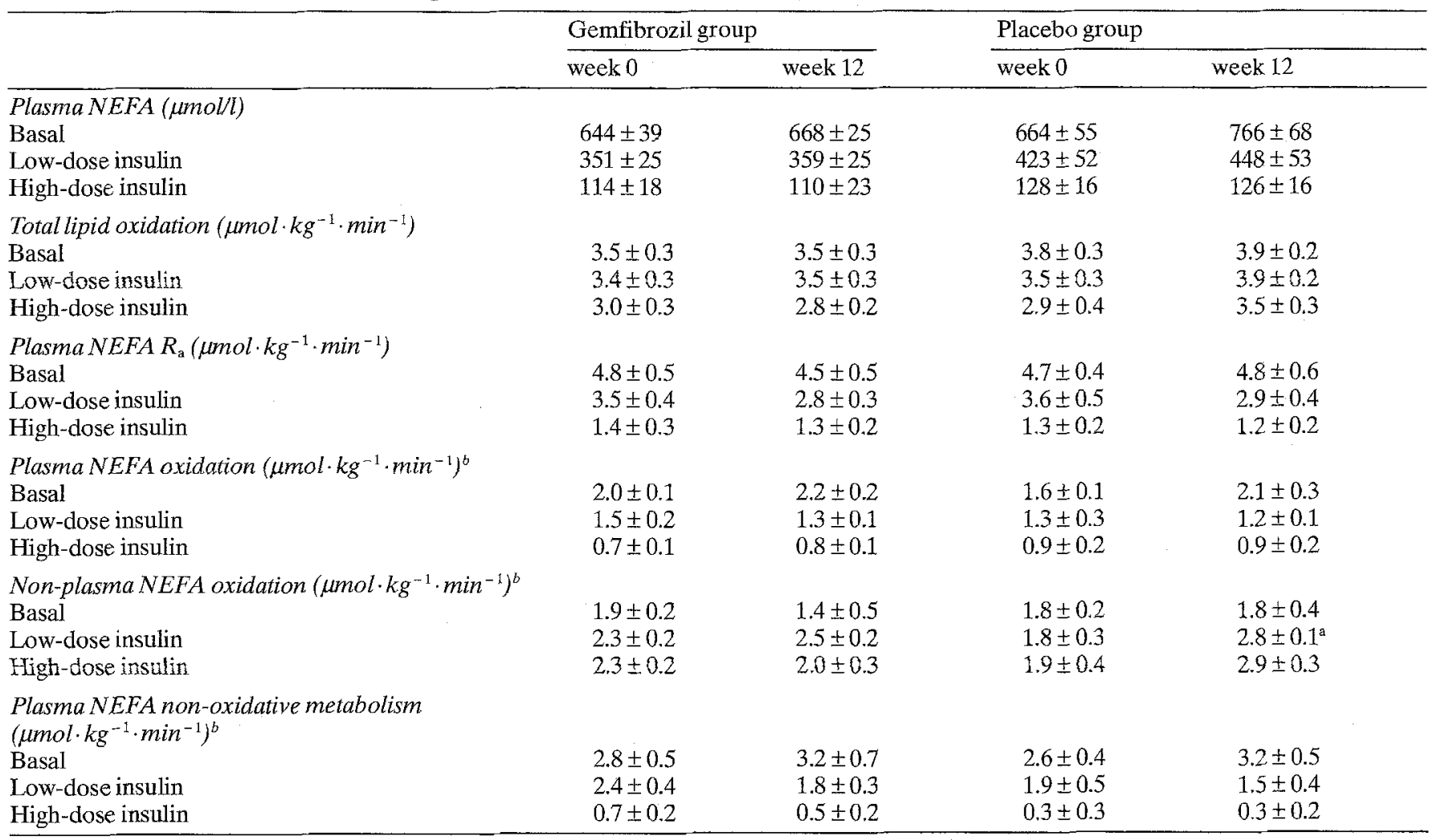

${ }^{9} p<0,05$ vs week $0,{ }^{6} n=6$ both in the gemfibrozil and placebo groups

Table 4. Glucose metabolism during the basal state and low-dose and high-dose insulin infusion

\begin{tabular}{|c|c|c|c|c|}
\hline & \multicolumn{2}{|c|}{ Gemfibrozil group } & \multicolumn{2}{|c|}{ Placebo group } \\
\hline & week 0 & week 12 & $\overline{\text { week } 0}$ & week 12 \\
\hline $\begin{array}{l}\text { Glucose } R_{0}\left(\mu \mathrm{mol} \cdot \mathrm{kg}^{-1} \cdot \mathrm{min}^{-1}\right) \\
\text { Basal } \\
\text { Low-dose insulin } \\
\text { High-dose insulin }\end{array}$ & $\begin{array}{l}11.9 \pm 0.5 \\
12.0 \pm 1.0 \\
16.2 \pm 1.7\end{array}$ & $\begin{array}{l}12.4 \pm 0.7 \\
11.8 \pm 0.5 \\
17.7 \pm 2.7\end{array}$ & $\begin{array}{l}11.9 \pm 0.9 \\
10.9 \pm 1.1 \\
17.1 \pm 4.2\end{array}$ & $\begin{array}{l}11.1 \pm 0.8 \\
10.7 \pm 1.1 \\
17.2 \pm 2.6\end{array}$ \\
\hline $\begin{array}{l}\text { Oxidative glucose } R_{\mathrm{d}}\left(\mu \mathrm{mol} \cdot \mathrm{kg}^{-1} \cdot \mathrm{min}^{-1}\right) \\
\text { Basal } \\
\text { Low-dose insulin } \\
\text { High-dose insulin }\end{array}$ & $\begin{array}{l}5.2 \pm 0.6 \\
5.4 \pm 0.5 \\
7.7 \pm 0.8\end{array}$ & $\begin{array}{l}5.2 \pm 0.6 \\
5.1 \pm 0.4 \\
7.6 \pm 0.6\end{array}$ & $\begin{array}{l}4.3 \pm 0.7 \\
5.1 \pm 0.8 \\
7.6 \pm 1.1\end{array}$ & $\begin{array}{l}4.1 \pm 0.4 \\
4.1 \pm 0.6 \\
5.9 \pm 0.7\end{array}$ \\
\hline $\begin{array}{l}\text { Non-oxidative glucose } R_{\mathrm{d}}\left(\mu \mathrm{mol} \cdot \mathrm{kg}^{-1} \cdot \mathrm{min}^{-1}\right) \\
\text { Basal } \\
\text { Low-dose insulin } \\
\text { High-dose insulin }\end{array}$ & $\begin{array}{l}6.7 \pm 0.9 \\
6.5 \pm 1.3 \\
8.6 \pm 1.2\end{array}$ & $\begin{array}{r}7.2 \pm 1.1 \\
6.7 \pm 0.8 \\
10.1 \pm 2.4\end{array}$ & $\begin{array}{l}7.6 \pm 1.3 \\
5.8 \pm 1.3 \\
9.6 \pm 4.4\end{array}$ & $\begin{array}{r}7.0 \pm 0.9 \\
6.6 \pm 1.2 \\
11.4 \pm 3.0\end{array}$ \\
\hline
\end{tabular}

Interrelations between glucose and lipid metabolism. Basal lipid oxidation at week 0 correlated positively with plasma NEFA concentrations $(r=0.46, p<0.05)$, the plasma NEFA turnover rate $(r=0.55, p<0.01)$ and plasma NEFA oxidation $(r=0.70, p<0.01)$. Basai glucose oxidation rates displayed an inverse correlation with lipid oxidation $(r=-0.87, p<0.001)$ and non-oxidative NEFA metabolism $(r=-0.59, p<0.05)$. There were no correlations between fasting serum total or VLDL triglycerides and basal lipid oxidation or insulin-stimulated glucose disposal at week 0 . No correlation between HDL-cholesterol concentration and insulin-stimulated glucose disposal at baseline was found.
Adverse effects. The serum creatine kinase concentration increased from 207 to $515 \mathrm{U} / 1$ (reference range 0-270 U/1 for men) in one patient after 8 weeks of gemfibrozil therapy, but was normal after 12 weeks of gemfibrozil therapy (143 U/1). The increment in serum creatine kinase was more likely to be caused by heavy muscle exercise than by gemfibrozil. No other adverse effects emerged.

\section{Discussion}

The relationships between insulin resistance, hypertriglyceridaemia and low HDL cholesterol are still unclear in Type 2 diabetes. The obvious question is what are the 
underlying mechanisms for these associations: is hypertriglyceridaemia and a low HDL cholesterol concentration a cause or a consequence of the insulin resistance found in Type 2 diabetes. To try to answer this question gemfibrozil was used to lower the concentration of serum triglycerides in Type 2 diabetic patients in a randomized double-blind placebo controlled study.

Although the lipid lowering effect of gemfibrozil is well-documented in non-diabetic subjects, its efficacy in diabetic subjects has not been well-established. In this trial gemfibrozil caused a significant reduction of both fasting total and VLDL and of postprandial triglyceride concentrations and a small but significant rise of HDL cholesterol concentration. The data are consistent with recent observations by Garg and Grundy [39] and Shen et al. [40]. The elevation of LDL cholesterol in the gemfibrozil group was not unexpected but the lowering of LDL cholesterol in the placebo group was puzzling as discussed elsewhere (Lahdenperä S, Tilly-Kiesi M, Vuorinen-Markkola H, Taskinen M-R, unpublished data). Gemfibrozil reduces LDL cholesterol in subjects belonging to the lowest tertiles of serum triglycerides but raises LDL cholesterol in subjects with moderate hypertriglyceridaemia [41]. Recently fibrates have been shown to shift the distribution of circulating LDL towards larger and less dense particles [42-44], which are considered to be less atherogenic than the small dense LDL particles [45]. Likewise, in the present study LDL particle size increased as reported in detail elsewhere (Lahdenperä $\mathrm{S}$ et al., unpublished data).

Recent studies have suggested that glycaemic control is not affected by gemfibrozil $[39,40]$. Clofibrate and bezafibrate have been reported to either slightly improve or to have no effect on glycaemic control in Type 2 diabetic patients [46-48]. In the present study $\mathrm{HbA}_{1 \mathrm{c}}$ levels tended to increase slightly in both groups but the increment was significant only in the gemfibrozil group. This was partly due to one patient in the gemfibrozil group who developed secondary failure during the treatment period. His $\mathrm{HbA}_{1 \mathrm{c}}$ increased from $7.9 \%$ to $10.1 \%$ during the study period and insulin treatment was initiated after the study. The fact that fasting blood glucose or insulin and 24-h glucose or insulin profiles determined in the standardized circumstances did not change in either group indicate that overall gemfibrozil had no effect on glycaemic control.

The present data demonstrate that gemfibrozil has no effect on either the glucoregulatory or antilipolytic action of insulin in Type 2 diabetic patients with moderate hypertriglyceridaemia although it significantly reduces the concentration of serum triglycerides. The results are consistent with the recent observation by Shen et al. [40]. However, when Shen et al. subgrouped the patients on the basis of initial glycaemic control the patients with fair control (fasting plasma glucose $>9.0 \mathrm{mmol} / \mathrm{l}$ ) demonstrated a slight improvement of insulin sensitivity. Since the study was not controlled it is impossible to exclude that the effect reflects only the intensity of investigator involvement in patient management. Steiner [49] found an improved insulin sensitivity determined by oral glucose tolerance test in non-diabetic subjects treated with gemfibrozil. However, the improvement was observed only in those subjects whose triglycerides decreased more than $1.7 \mathrm{mmol} / 1$. The present data do not exclude the possibility that correction of severe hypertriglyceridaemia may improve insulin sensitivity. On the other hand insulin sensitivity (measured using the insulin clamp technique) has remained unchanged during bezafibrate treatment despite the marked lowering of total and VLDL triglyceride levels [48, 50].

The present study also provides information, derived from indirect calorimetry, on the intracellular fate of glucose during gemfibrozil vs placebo treatments. The data show that gemfibrozil had no effect on either basal or insulin-stimulated glucose oxidation or non-oxidative metabolism. Unlike previous studies, we could not find any correlation between baseline serum triglycerides and insulin-stimulated glucose disposal. However, our patients were in moderate metabolic control and consequently variation in these parameters was relatively small. Moreover lowering of triglycerides did not modulate lipid oxidation in the basal state or during insulin infusion as would be expected if hypertriglyceridaemia would increase lipid oxidation.

The second aim of this study was to test if gemfibrozil has any antilipolytic action. Theoretically, lowering of plasma NEFA concentrations could improve insulin sensitivity of glucose utilization via substrate competition between glucose and lipids [11, 12, 51, 52]. In the present study we could not observe any differences of 24-h plasma NEFA profiles between gemfibrozil and placebo groups. Also, rates of NEFA and lipid oxidation in the basal state and during the insulin infusion were not influenced by gemfibrozil in the present study. Thus, the data do not support the concept that gemfibrozil would have been antilipolytic in man.

In conclusion the present data support the concept, that lowering of serum triglycerides does not improve insulin sensitivity in Type 2 diabetic patients with moderate hypertriglyceridaemia. However, gemfibrozil can be advocated for treatment of lipid abnormalities in Type 2 diabetic patients because it has beneficial action on both hypertriglyceridaemia and low HDL cholesterol which are the major lipid abnormalities in Type 2 diabetes.

Acknowledgements. We thank Ms E. Kostamo, Ms R. Kärkkäinen, Mrs H. Hilden and Ms S. Rannikk o for superb technical assistance in performing these studies, and the patience of the volunteers. This work was supported by grants from the Finnish State Medical Research Council, the Sigrid Juselius Foundation and the Paavo Nurmi Foundation, Helsinki, Finland and from the Warner-Lambert Company, Ann Arbor, Michigan, USA.

\section{References}

1. Abbott WGH, Lillioja S, Young AA et al. (1987) Relationships between plasma lipoprotein concentrations and insulin action in an obese hyperinsulinaemic population. Diabetes 36: 897-904

2. Yki-Järvinen H, Taskinen M-R (1988) Interrelationships among insulin's antilipolytic and glucoregulatory effects and plasma triglycerides in nondiabetic and diabetic patients with endogenous hypertriglyceridemia. Diabetes 37:1271-1278 
3. Laakso M, Sarlund H, Mykkänen L (1990) Insulin resistance is associated with lipid and lipoprotein abnormalities in subjects with varying degrees of glucose tolerance. Arteriosclerosis 10 : 223-231

4. McKane WR, Stevens AB, Woods R, Andrews WJ, Henry RW, Bell PM (1990) The assessment of hepatic and peripheral insulin sensitivity in hypertriglyceridemia. Metabolism 39: 1240-1245

5. Bazelmans J, Nestel PJ, Nolan C (1983) Insulin-induced glucose utilization influences triglyceride metabolism. Clin Sci 64: 511 516

6. Ginsberg HN (1991) Lipoprotein physiology in nondiabetic and diabetic states, relationship to atherogenesis. Diabetes Care 14: $839-855$

7. Reaven GM (1987) Abnormal lipoprotein metabolism in non-insulin-dependent diabetes mellitus. Pathogenesis and treatment. Am J Med 83 [Suppl 3 A]: 31-40

8. Howard BV (1987) Lipoprotein metabolism in diabetes mellitus. J Lipid Res 28: 613-628

9. Haffner SM, Valdez RA, Hazuda HP, Mitchell BD, Morales PA, Stern MP (1992) Prospective analysis of the insulin-resistance syndrome (syndrome X). Diabetes 41: 715-722

10. Groop LC, Bonadonna RC, Del Prato S et al. (1989) Glucose and free fatty acid metabolism in non-insulin-dependent diabetes mellitus: evidence for multiple sites of insulin resistance. J Clin Invest 84: 205-213

11. Ferrannini E, Barrett EJ, Bevilacqua S, DeFronzo RA (1983) Effect of fatty acids on glucose production and utilization in man. $J$ Clin Invest 72: 1737-1747

12. Yki-Järvinen H, Puhakainen I, Koivisto VA (1991) Effect of free fatty acids on glucose uptake and nonoxidative glycolysis across human forearm tissues in the basal state and during insulin stimulation. J Clin Endocrinol Metab 72: 1268-1277

13. Vessby B, Boberg M, Lithell H (1986) Influence of gemfibrozil on lipoprotein composition: triglyceride removal capacity and fatty acid composition of the plasma lipid esters. In: Further progress with gemfibrozil. Royal Society of Medicine Services, London, pp 1-10

14. Kesäniemi YA, Grundy SM (1984) Influence of gemfibrozil and clofibrate on metabolism of cholesterol and plasma triglycerides in man. JAMA 251: 2241-2246

15. Kissebah AH, Adams PA, Wynn V (1976) Lipokinetic studies with gemfibrozil. Proc R Soc Med 69: 94-97

16. Elkeles RS, Ashwell M, Priest R, Durrant M (1976) The effect of CI-719 on lipolysis in rat adipose tissue. Proc R Soc Med 69 [Supp12]: 98-100

17. Carlson LA (1976) Effect of gemfibrozil in vitro on fat-mobilizing lipolysis in human adipose tissue. Proc R Soc Med 69 [Suppl 2]: 101-103

18. DeFronzo RA, Tobin JD, Andreas R (1979) Glucose clamp technique: a method of quantifying insulin secretion and resistance. Am J Physiol 237: E214-E223

19. Yki-Järvinen H, Young AA, Lamkin C, Foley JE (1987) Kinetics of glucose disposal in whole body and across the forearm in man. $\mathrm{J}$ Clin Invest 79: 1713-1719

20. Yki-Järvinen H, Consoli A, Nurjhan N, Young AA, Gerich JE (1989) Mechanisms for underestimation of isotopically determined glucose disposal. Diabetes 38: 744-751

21. Koivisto VA, Yki-Järvinen H, Puhakainen I, Virkamäki A, DeFronzo R (1990) No evidence for isotope discrimination of tritiated glucose tracers in measurements of glucose turnover rates in man. Diabetologia 33: 168-173

22. Bergman RN, Finegood DT, Ader M (1985) Assessment of insulin sensitivity in vivo. Endocrine Rev 6: 45-86

23. Steele R (1959) Influences of glucose loading and of injected insulin on hepatic glucose output. Ann NY Acad Sci 82: 420-430

24. Yki-Järvinen H, Puhakainen I, Saloranta C, Groop L, Taskinen M-R (1991) Demonstration of a novel feedback mechanism between FFA oxidation from intracellular and intravascular sources. Am J Physiol 260: E680-E689

25. Ferrannini E (1988) The theoretical bases of indirect calorimetry: a review. Metabolism 37:287-301
26. Taskinen M-R, Bogardus C, Kennedy A, Howard BV (1985) Multiple disturbances of free fatty acid metabolism in noninsulin-dependent diabetes. Effect of oral hypoglycemic therapy. J Clin Invest 76: 637-644

27. Roberts I, Smith IM (1986) A simple method for the measurement of glycerol in serum. Ann Clin Biochem 23: 490-491

28. Miles J, Glasscock R, Aikens J, Gerich J, Haymond MA (1983) Microfluorometric method for the determination of free fatty acids in plasma. J Lipid Res 24: 96-99

29. Allsop JR, Wolfe RR, Burke JF (1978) Tracer priming of the bicarbonate pool. J Appl Physiol 45: 137-139

30. Bonadonna RC, Groop LC, Zych K, Shank M, DeFronzo RA (1990) Dose-dependent effect of insulin on plasma free fatty acid turnover and oxidation in humans. Am J Physiol 259: E736-E750

31. Hagenfeldt L (1975) Turnover of individual free fatty acids in man. Fed Proc 34: 2246-2249

32. Lewis B, Mancini M, Mattock M, Chait A, Fraser TR (1972) Plasma triglyceride and fatty acid metabolism in diabetes mellitus. Eur J Clin Invest 2: 445-453

33. Jensen MD, Heiling V, Miles JM (1990) Measurement of nonsteady-state free fatty acid turnover. Am J Physiol 258: E103E108

34. Kadish AH, Little RL, Sternberg JC (1968) A new and rapid method for the determination of glucose by measurement of rate of oxygen consumption. Clin Chem 14: 116-131

35. Gennaro WD, van Norman JD (1975) Quantitation of free, total and antibody-bound insulin in insulin-treated diabetics. Clin Chem 21: 873-879

36. Kuzuya H, Blix PM, Horwitz DL, Steiner DF, Rubenstein AH (1977) Determination of free and total insulin and C-peptide in insulin-treated diabetics. Diabetes 26: 22-29

37. Cole RA, Soeldner JS, Dunn PJ, Bunn HF (1978) A rapid method for the determination of glycosylated hemoglobins using high-performance liquid chromatography. Metabolism 27: 289301

38. Taskinen M-R, Kuusi T, Helve E, Nikkilä EA, Yki-Järvinen $H$ (1988) Insulin therapy induces antiatherogenic changes of serum lipoproteins in noninsulin-dependent diabetes. Arteriosclerosis 8:168-177

39. Garg A, Grundy SM (1989) Gemfibrozil alone and in combination with lovastatin for treatment of hypertriglyceridemia in NIDDM. Diabetes 38: 364-372

40. Shen DC, Fuh MMT, Shieh SM, Chen IYD, Reaven GM (1991) Effect of gemfibrozil treatment in sulfonylurea-treated patients with noninsulin-dependent diabetes mellitus. J Clin Endocrinol Metab 73: 503-510

41. Mänttäri M, Koskinen P, Manninen V, Huttunen JK, Frick MH, Nikkilä EA (1990) Effect of gemfibrozil on the concentration and composition of serum lipoproteins. A controlled study with special reference to initial triglyceride levels. Atherosclerosis 81: $11-17$

42. Eisenberg S, Gavish D, Oschry Y, Fainaru M, Deckelbaum RJ (1984) Abnormalities in very low, low, and high density lipoproteins in hypertriglyceridemia. Reversal toward normal with bezafibrate treatment. J Clin Invest 74: 470-482

43. Shepherd J, Griffin B, Caslake M, Gaw A, Packard C(1991) The influence of fibrates on lipoprotein metabolism. In: Gotto AM, Paoletti R (eds) Atherosclerosis Reviews. Raven Press, New York, pp 163-169

44. Tilly-Kiesi M, Tikkanen M (1991) Low density lipoprotein density and composition in hypercholesterolaemic men treated with HMG CoA reductase inhibitors and gemfibrozil. J Intern Med 229: 427-434

45. Austin MA, Breslow JL, Hennekens CH (1988) Low density lipoprotein subclass patterns and risk of myocardial infarction. JAMA 260: 1917-1921

46. Kobayashi M, Shigeta Y, Hirata Y et al. (1988) Improvement of glucose tolerance in NIDDM by clofibrate. Randomized doubleblind study. Diabetes Care 11: 495-499

47. Jones IR, Swai A, Taylor R, Miller M, Laker MF, Alberti KGMM (1990) Lowering of plasma glucose concentrations with beza- 
fibrate in patients with moderately controlled NIDDM. Diabetes Care 13: 855-863

48. Riccardi G, Genovese S, Saldalamacchia G et al. (1989) Effects of bezafibrate on insulin secretion and peripheral insulin sensitivity in hyperlipidemic patients with and without diabetes. Atherosclerosis 75: 175-181

49. Steiner G (1991) Altering triglyceride concentrations changes insulin-glucose relationships in hypertriglyceridemic patients. Double-blind study with gemfibrozil with implications for atherosclerosis. Diabetes Care 14: 1077-1081

50. Karhapää P, Uusitupa M, Voutilainen E, Laakso M. Effects of bezafibrate on insulin sensitivity and glucose tolerance in subjects with combined hyperlipidemia. Clin Pharm Therapeutics (in press)

51. Randle PJ, Hales CN, Garland PB, Newsholme EA (1963) The glucose fatty-acid cycle, its role in insulin sensitivity and the metabolic disturbances of diabetes mellitus. Lancet I: 785-789
52. Saloranta C, Franssila-Kallunki A, Ekstrand A, Taskinen M-R, Groop L (1991) Modulation of hepatic glucose production by non-esterified fatty acids in type 2 (non-insulin-dependent) diabetes mellitus. Diabetologia 34: 409-415

Received: 7 July 1992 and in revised form: 12October 1992

Dr. H. Vuorinen-Markkola

Second Department of Medicine

Haartmaninkatu 4

SF-00290 Helsinki

Finland 